\title{
ASSENTADAS NO CIRCUITO DO PRONAF MULHER: EXPRESSÕES DA AUTONOMIA FEMININA?
}

\author{
Lais Tubero Izidoro \\ Vera Lúcia Silveira Botta Ferrante ${ }^{2}$ \\ Henrique Carmona Duval \\ Daiane Roncato Cardozo \\ Helena Carvalho De Lorenzo
}

RESUMo: O presente artigo é resultado de uma pesquisa que teve por objetivo verificar a operacionalização das políticas públicas voltadas para as mulheres, especialmente o Pronaf Mulher, buscando compreender os desafios de sua execução no assentamento Monte Alegre, Araraquara/SP. A metodologia foi composta de uma revisão bibliográfica sobre o tema, trabalho de campo a fim de se conhecer como ocorrem as relações de gênero no assentamento e a influência da política pública, aplicação de entrevistas com roteiro semiestruturado a mulheres assentadas e gestores. Procurouse identificar os avanços e os entraves que ainda existem em relação à participação das mulheres nos espaços institucionais. Como resultados, pode-se afirmar que o Pronaf Mulher não está sendo acessado pela maioria das trabalhadoras no assentamento pesquisado em função das assimetrias de poder existentes dentro do núcleo familiar das assentadas e no campo social do assentamento como um todo. A falta de informação e de diálogo nas relações entre assentadas e agentes técnicos foi apontada como um dos principais entraves de acesso das mulheres a esta política pública.

Palavras-chave: Pronaf Mulher; Relações de gênero; Políticas públicas; Assentamentos rurais; Participação social.

'Mestre em Desenvolvimento Territorial e Meio Ambiente pela Universidade de Araraquara - UNIARA. ${ }^{2}$ Coordenadora e Docente do Programa de Pós-Graduação em Desenvolvimento Territorial e Meio Ambiente da UNIARA.

Docente da Universidade Federal de São Carlos - UFSCar, Campus Lagoa do Sino, Buri.

${ }^{4}$ Pesquisadora de Pós-Doutorado do Programa de Pós-Graduação em Desenvolvimento Territorial e Meio Ambiente da UNIARA.

${ }^{5}$ Docente e Vice-coordenadora do Programa de Pós-Graduação em Desenvolvimento Territorial e Meio Ambiente da UNIARA.

ABSTRACT: This article is the result of a research that aimed to verify the operationalization of the public policies directed at women, especially Pronaf Mulher, seeking to understand the challenges of their execution in the Monte Alegre, Araraquara / SP settlement. The methodology was composed of a literature review on the subject, fieldwork in order to know how gender relations occur in the settlement and the influence of public policy, the application of semi-structured interviews with settled women and managers. It sought to identify the advances and obstacles that still exist in relation to the participation of women in institutional spaces. As a result, it can be affirmed that Pronaf Mulher is not being accessed by the majority of the workers in the settlement researched due to the asymmetries of power existing within the family nucleus of the settlers and in the social field of the settlement as a whole. The lack of information and dialogue in the relations between the settlers and technical agents was pointed out as one of the main obstacles for women to have access to this public policy.

KEYwords: Pronaf Women; Gender relations; Public policy; Rural settlements; Social participation.

\section{INTRODUÇão}

A complexidade dos assentamentos pode ser dimensionada por apresentar novas relações de produção e de trabalho, promover uma redistribuição nos sistemas produtivos territoriais e novas perspectivas quanto à reprodução da vida material das famílias. Na condição de assentados, por muitas vezes inédita, os trabalhadores deparam-se com problemas relativos à organização política e econômica. Uma das esferas de repercussão destas implicações se refere à situação das mulheres assentadas, grupo social que está em constante luta para a conquista de seus direitos. O objetivo do estudo foi analisar a possível influência do Programa Nacional de Fortalecimento da Agricultura - Pronaf Mulher na situação das mulheres do assentamento Monte Alegre.

Durante a pesquisa foram feitas entrevistas semiestruturadas procurando verificar como se dão as expressões da dominação masculina nos diferentes atores e espaços que compõem o processo para a obtenção do Pronaf Mulher. Este Programa se constitui como uma modalidade do Pronaf voltado às mulheres da agricultura familiar. Foi selecionado como objeto de estudo em razão da baixa procura e número de contratos desta modalidade, apesar do crescimento do movimento de mulheres rurais nos últimos anos. 
A bibliografia utilizada advém principalmente de estudos já realizados pelo Núcleo de Pesquisa e Documentação Rural (NUPEDOR/UNIARA) sobre o desenvolvimento dos assentamentos rurais, incluindo projetos com recorte nas relações de gênero e nas políticas públicas voltadas às mulheres assentadas. As principais conclusões destes projetos apontam que apesar das conquistas como a titulação conjunta, novos créditos e assistência técnica específicos para mulheres, ainda persistem expressões de patriarcalismo tanto no interior das famílias assentadas como por parte do projeto estatal de assentamentos (FERRANTE et al., 2012).

São sistemas de controle culturalmente enraizados, que normalmente fazem uma alusão ao caráter de "ajuda" em relação ao trabalho das mulheres, sem reconhecer que elas são as principais responsáveis pelo trabalho em sistemas produtivos no interior das pequenas propriedades, sobretudo os quintais com produção de hortas, aves e suínos, muitas vezes identificados com práticas agroecológicas (SILIPRANDI, 2011). Por outro lado, tem-se constatado que as mulheres exercem atividades também em outros sistemas de produção, inclusive os comerciais, mas suas atividades não se restringem à esfera agrícola, pois participam de atividades não-agrícolas dentro e fora das propriedades rurais (BRUMER, 2004)). Acredita-se, portanto, que sem o devido reconhecimento da importância dos papéis das mulheres no desenvolvimento rural, as políticas públicas a elas direcionadas podem reproduzir tal preconceito de que seu trabalho é ajuda, e o crédito específico para mulheres financiar atividades que não sejam aquelas de seu interesse.

As pesquisas apontaram ainda um crescimento do protagonismo das mulheres na formação de grupos formais, como as associações de mulheres, que atuam na produção e no processamento de produtos antes tipicamente voltados ao autoconsumo (ESMERALDO, 2008). Especificamente em Araraquara, por meio da organização e da interlocução das mulheres na esfera local suas reivindicações se concretizaram em espaços de produção, como uma padaria e uma cozinha multiuso. A partir disso, seus produtos alcançaram mercados urbanos abertos também por uma política de inclusão produtiva em feiras municipais (FERRANTE; DUVAL, 2009).

A partir das informações destas investigações preliminares foram realizados trabalhos de campo e entrevistas semiestruturadas, que tiveram como objetivo identificar nas falas das entrevistadas expressões de dominação masculina que ocorrem tanto dentro do campo - lote e casa - representada principalmente pelo marido, como no espaço urbano, representada pelos agentes de assistência técnica. Também foi realizado um levantamento de dados secundários em endereços eletrônicos governamentais, acerca da execução do Pronaf Mulher no âmbito da agricultura familiar, com o objetivo de compreender os objetivos e mensurar a participação desta modalidade de financiamento no montante geral de contratos do Pronaf.

Por meio das entrevistas foi possível detectar lacunas de compreensão entre as mulheres assentadas e os agentes institucionais, dado que os projetos e expectativas, relativos à renda das mulheres não são conhecidos pela instituição que presta assistência técnica.

A coleta de dados secundários se fez por meio do acesso à Matriz de Dados do Crédito Rural vinculada ao Banco Central do Brasil. Neste site é apresentada uma extensa variável de informações relacionadas ao crédito rural e apresenta-se como opção de consulta verificar alguns dados relacionados ao Pronaf a partir do ano de 2013 até o ano de 2016, já que nos anos anteriores as informações estão sistematizadas no Anuário Estatístico de Crédito Rural. Todavia, estes anuários não fornecem a descrição das linhas do Pronaf nos dados apresentados. Também não constam informações sobre o histórico de acesso ao Pronaf Mulher em Araraquara, mas foi possível selecionar dados referentes ao cenário estadual, o que pôde auxiliar a delinear hipóteses referentes ao acesso das trabalhadoras assentadas do Monte Alegre ao Pronaf Mulher.

Importante salientar que o Pronaf Mulher surge como forma de atender parte da demanda das mulheres rurais, e aumentar a participação das mulheres no Pronaf. O Ministério do Desenvolvimento agrário emite uma portaria n. 121 em 22 de maio de 2001 que determina uma participação mínima de 30\% de mulheres no programa. Por meio da Campanha de Crédito para a Igualdade das Trabalhadoras Rurais, no plana Safra 2004/2005, entra em vigor o Pronaf Mulher, sob os seguintes pressupostos: a) construir estratégias de acesso das mulheres e jovens trabalhadoras ao Pronaf-crédito; b) desburocratizar e garantir o acesso das mulheres e jovens ao Pronaf e aos fundos constitucionais, para atender atividades agrícolas e não agrícolas, assegurando carência e prazos de pagamento diferenciados para as mulheres trabalhadoras rurais. (HERNANDEZ, 2009). É importante deste contexto que se considere a ausência da mulher no crédito rural ao longo de toda sua história enquanto agricultora familiar.

Ainda que a democratização do acesso ao crédito tenha sido o principal norteador da formulação do Pronaf Mulher, foi possível diagnosticar que 
as mulheres do Assentamento Monte Alegre não têm tido acesso ao Pronaf Mulher e que isso se deve a um conjunto de fatores, que se expressam sobretudo em relação à falta de informação e à ineficiência do Pronaf Mulher em se diferenciar das outras modalidades de crédito, fazendo com que seja uma política voltada para as mulheres apenas por conta da nomenclatura, sem representar, efetivamente, elementos concretos da conquista da sua autonomia.

\section{O ASSEntamento Monte Alegre: espaço da inVestigação}

O Projeto de Assentamento da Fazenda Monte Alegre está localizado em uma área pertencente ao Governo do estado de São Paulo, a qual possui 6.595, 19 ha, e abrange a zona rural dos municípios de Araraquara, Motuca e Matão. É dividido em seis núcleos sendo que destes, dois (III e VI) se localizam no município de Araraquara. Pela proximidade com a cidade e pela característica do terreno, a região foi explorada para o cultivo de eucalipto até 1985, pela Companhia de Desenvolvimento Agrícola do estado de São Paulo - CODASP, período que vai coincidir com o I Plano de Reforma Agrária (CAMPOI, 2005).

Figura 1 - Mapa da localização do Assentamento Monte Alegre.

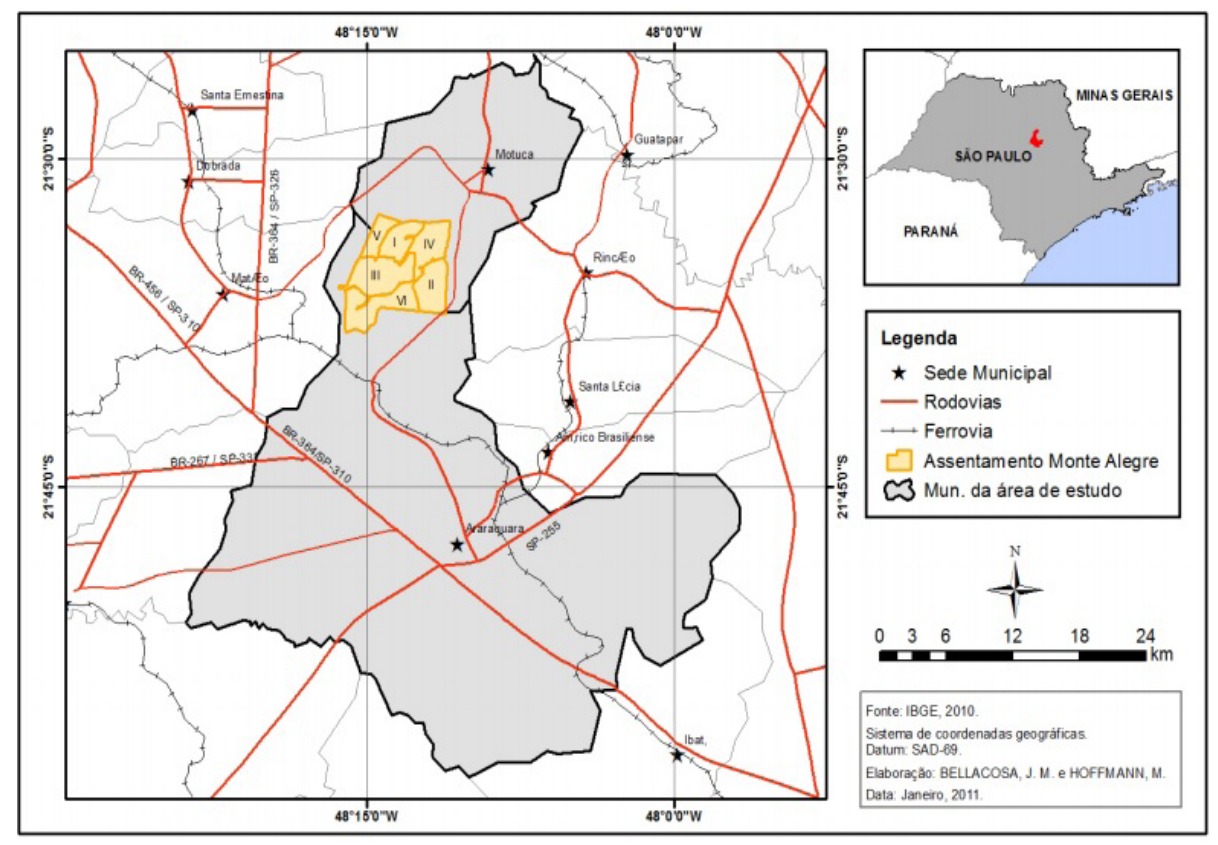

Fonte: BELLACOSA; HOFFMANN, 2010.
O órgão gestor e responsável por dar assistência técnica aos assentados é a Fundação Instituto de Terras do Estado de São Paulo (ITESP). Foi por meio deste órgão que os primeiros núcleos foram instalados, entre os anos de 1985 e 1986, sendo que os demais núcleos só foram instalados dez anos depois (FERRANTE; DUVAL, 2009). Atualmente, residem 418 famílias no assentamento Monte Alegre, sendo que é no núcleo VI que há maior concentração de famílias.

A criação do assentamento se deu em um cenário de expansão dos movimentos grevistas de boias-frias, que tiveram destaque nacional pelas greves de Guariba (FERRANTE, 1992; BARONE, 2002). Estas greves, conforme detalha Ferrante et al. (2012), se deram como forma de reivindicar os direitos trabalhistas que não estavam sendo respeitados nas usinas canavieiras. Era marcante a exploração do trabalho que, por muitas vezes, tinha como consequência adoecimentos. Conforme começou a haver repressões e perseguições políticas dentro dos movimentos grevistas, houve uma pressão por parte dos boias-frias para a obtenção de terra (FERRANTE et al., 2012).

\section{DO DIREITO AO VOTO À INSERÇÃO NAS POLÍTICAS PÚBLICAS: UMA BREVE} TRAJETÓRIA DO FEMINISMO

Os assentamentos se fazem enquanto um produto de luta pela reforma agrária, e neste contexto de conquista, o papel da mulher se apresenta oscilante, já que embora sejam atuantes no processo de conquista, têm seu papel secundarizado na dimensão familiar e produtiva nos lotes dos assentamentos (BARONE et al., 2012).

Foram vários os avanços ao longo do tempo, possibilitados pela luta feminista em relação aos direitos das mulheres. Entretanto é importante refletir que embora mitigadas, as formas de dominação ainda existem e, na medida do tempo, se tornaram mais complexas, às vezes camufladas em uma teia de invisibilidades.

Quando se fala em dominação masculina, admitem-se as modificações sofridas nas instituições patriarcais, que pelas transformações nos processos de subordinação da mulher pelo homem, assume-se como uma expressão mais geral do que patriarcado. Miguel e Biroli (2014) relata que esta dominação masculina foi construída ao longo da história e sempre coexistiu com alguma forma de resistência das mulheres, ora mais ou menos organizadas politicamente. $\mathrm{O}$ feminismo em sua trajetória, segundo Miguel e 
Biroli (2014, p.19), "se definiu pela construção de uma crítica que vincula a submissão da mulher na esfera doméstica à sua exclusão da esfera pública". Apresenta como exemplo as discrepâncias que ocorriam nas lutas travadas pelo feminismo nos séculos XVIII e XIX, em que as escravas não eram consideradas parte do movimento e não tinham espaço de fala.

Dada a origem da sociedade brasileira, constituída sobre pilares escravocratas, que tinha como consequência sobretudo a concentração fundiária e a desigualdade social, fez-se necessário que uma parcela da população feminina se inserisse no mercado de trabalho, ocupando o espaço público, destinado aos homens (NADER, 2005). Esta inserção se fez restrita aos elementos econômicos e não possibilitou de imediato uma emancipação política e assim os homens continuaram a dominar os espaços e todos os aspectos relacionados com a vida das mulheres. Deste modo, "na passagem do patriarcado colonial para o contratualismo liberal, a autoridade e o privilégio masculinos seguiram predominando nas esferas pública e doméstica" (MOLYNEUX, p. 30 apud AZEVEDO, 2017).

Avançando para as décadas de 1960 e 1970 no Brasil, o feminismo elaborou importantes reflexões a partir de Heleieth Saffioti e Elizabeth SouzaLobo, sobretudo referentes ao patriarcado e às desigualdades subjacentes ao trabalho das mulheres, entre outras, que contribuíram significativamente para o avanço das pautas femininas no Brasil. O patriarcado, ou dominação masculina como é conceituado por alguns autores e autoras, foi objeto de estudo de diversos trabalhos, como nos estudos do sociólogo Max Weber que define dominação masculina como o estabelecimento de vínculos pessoais entre o senhor, os demais membros da família e os servos, e tem como fundamento a autoridade do chefe da família ou comunidade doméstica. Essa autoridade se baseia na tradição, ou seja, "na crença da inviolabilidade daquilo que foi assim desde sempre" (WEBER, 1991, p. 234).

Essa construção histórica foi responsável por apresentar perspectivas e direcionar o feminismo contemporâneo. Os diversos caminhos trilhados para a inserção das pautas feministas nos debates midiáticos e na sociedade como um todo foram essenciais para que as mulheres conseguissem se articular para responder de uma forma cada vez mais firme aos problemas que vão se modificando ao longo do tempo, mas que possuem as mesmas raízes.

Em relação ao debate sobre espaço público e espaço privado, existem diferentes perspectivas que foram se estruturando ao longo da construção do pensamento feminista. A naturalidade dada à divisão sexual entre público e privado foi e vem sendo intensamente criticada pelas feministas. A dualidade colocada no debate é criticada por Miguel e Biroli (2014), que interpretam a divisão entre público e privado como uma forma de esvaziar o teor político das relações privadas, como se as relações de poder não fossem intrínsecas à política.

Esta relação entre o espaço privado e as mulheres dificulta a intervenção do Estado sobre as opressões que estas sofrem dentro de casa. Ela também corrobora para a ideia de que a mulher deve se resguardar e assumir exclusivamente seu papel de cuidadora, sendo considerado como "desvios", como Miguel e Biroli (2014) sugerem, sua inserção na esfera política, nos espaços de poder público (Câmara de vereadores, Câmara dos deputados, entre outras representações).

A autora chama a atenção para o fato de que o espaço público não representa o espaço de debate entre iguais, já que devido à dominação masculina, as mulheres não se encontram nos mesmos ou ocupam posições menores e, portanto, para que o debate avance, seria necessário a superação das desigualdades na esfera privada. Tendo em vista que as mulheres não ocupam com igualdade os espaços políticos, pode-se analisar que dificilmente as políticas públicas elaboradas nestes espaços irão contemplálas na esfera privada, sem que haja alguma pressão por parte destas. "O feminismo mostra, assim, que é impossível descolar a esfera política da vida social, a vida pública da vida privada, quando se tem como objetivo a construção de uma sociedade democrática" (MIGUEL; BIROLI, 2014, p.33).

Portanto, avaliar como as mulheres são incluídas socialmente por meio das políticas públicas é uma tarefa complexa, já que nem sempre a existência de uma política pública é garantia da efetividade do que ela se propõe a fazer. Além disso, a própria definição de política pública também se coloca de modo plural (SOUZA, 2006).

Para o presente artigo, é fundamental observar as políticas públicas voltadas para as mulheres e tentar entender que diferenças elas fazem para a sua vida produtiva no lote. Se no contexto de luta pela terra, por vezes, as relações patriarcais são superadas pela necessidade de homens e mulheres estarem na militância política, é sabido que, no âmbito do lote, as igualdades são sufocadas pelos papéis sociais impostos e muitas vezes encenados como marcas de uma cidadania tutelada.

O Pronaf Mulher: conquista Da aUtonomia Da MUlher Por Meio 


\section{DO CRÉDITO?}

Conforme destacam diferentes autores (ALVES, 2012; ZORZI, 2008) o acesso ao crédito se torna um tema extremamente relevante quando se coloca em análise a condição da mulher no meio rural, já que pode permitir a apropriação de um projeto econômico e possibilitar a autonomia financeira das trabalhadoras rurais.

Levando em consideração que o empoderamento da mulher se estrutura por meio da modificação das relações de gênero, Hernandez (2009) avalia fatores que poderiam garantir sua autonomia econômica e sua representação social e política. Desta forma, é importante avaliar os efeitos das políticas de crédito rural no cotidiano das mulheres rurais, principalmente as políticas de crédito que receberam, por meio de muitas lutas, um recorte de gênero. É o caso, por exemplo, do Pronaf Mulher, que se faz como um eixo de gênero dentro do Pronaf. Neste trabalho não há a intenção de realizar análise em profundidade do Pronaf, visto a existência de uma vasta gama de trabalhos que executam esta tarefa.

O que se pretende é realizar uma breve discussão tanto do processo histórico de sua criação quanto da sua caracterização para fornecer elementos que auxiliem na interpretação e análise da inserção das mulheres nesta política de crédito.

Segundo o Ministério do Desenvolvimento Agrário (MDA), o Programa Nacional de Fortalecimento da Agricultura Familiar (Pronaf) tem o intuito de financiar projetos individuais ou coletivos, que gerem renda aos agricultores familiares e assentados da reforma agrária. É assegurado as mais baixas taxas de juros dos financiamentos rurais e por isso uma das menores taxas de inadimplência entre os sistemas de crédito do país. Ainda segundo informações contidas no site, o agricultor deve estar com o CPF regularizado e livre de dívidas. As condições de acesso ao Crédito Pronaf, formas de pagamento e taxas de juros correspondentes a cada linha são definidas, anualmente, a cada Plano Safra da Agricultura Familiar, divulgado entre os meses de junho e julho (BRASIL, 2018). Desde sua criação, o Pronaf passou por diversas modificações objetivando contemplar um maior número de trabalhadores rurais. Conforme Fernandes (2008):

O Pronaf está dividido em três modalidades: investimento, custeio e infraestrutura. $\mathrm{O}$ crédito de custeio destina-se ao financiamento das atividades agropecuárias e não agropecuárias, enquanto o crédito de investimento destina-se às benfeitorias da propriedade. Essas duas modalidades podem ser acessadas de modo individual, coletivo ou grupal, obedecendo ao enquadramento da propriedade nos grupos [...] (FERNANDES, 2008, p.14).

Brummer e Spanavello (2012) apresentam uma configuração do acesso ao Pronaf, baseadas no Censo Agropecuário de 2006. Analisando o acesso ao recurso, as autoras explicam que se diferenciam os agricultores familiares e não familiares pelas respostas à não utilização do crédito, já que o número de agricultores que responderam não precisar do crédito foi maior para os enquadrados como não familiares ao mesmo tempo em que é maior o número de agricultores familiares que não acessaram o crédito por medo de ficarem inadimplentes. Diante deste cenário, constata-se uma tendência à concentração de recursos aos mais capitalizados.

No caso das mulheres, a questão da assimetria de poder derivada da desigualdade de gênero se insere como um entrave a mais dentro dos contrapontos na operacionalização do Pronaf. Ainda que o Pronaf seja direcionado para participação familiar, o homem é encarado como elemento central, fato este que "acaba excluindo as mulheres das esferas de discussão e interlocução com o Estado" (ZORZI, 2008, p.53). Cientes destas dificuldades, as mulheres rurais se organizam politicamente e reivindicam junto ao Estado uma série de direitos que pudessem permitir desenvolvimento da mulher no campo. Conforme já mencionado, uma das consequências das mobilizações realizadas pelas mulheres rurais foi a criação da linha Pronaf Mulher.

Conforme analisa De Melo (2003), “o Pronaf enquanto política pública não foi pensado enquanto um projeto que poderia instrumentalizar a mulher agricultora para que ela pudesse resolver seus próprios problemas em relação à dominação masculina" (DE MELO, 2003, p. 118). Isso significa que não houve a preocupação em se incorporar as questões de gênero no programa. Contudo, assim como outros programas e políticas públicas, conforme ocorre seu desenvolvimento, vão se modificando algumas características a fim de se alcançar um melhor desempenho ou uma melhor aplicabilidade na região que será executado.

No caso do Pronaf Mulher, a mesma unidade familiar pode contratar até dois financiamentos. O crédito disponibilizado é de até $\mathrm{R} \$ 50.000,00$, com juros que variam de $1 \%$ a $2 \%$ a.a., de acordo com o valor de financiamento, que pode ser pago em até dez anos, incluindo os três primeiros de carência 
(BANCO DO BRASIL, 2018). As mulheres estão presentes de modo significativo no campo, ainda assim, não representam com muita expressão o acesso ao crédito, principalmente no Pronaf Mulher. Em relação ao acesso no Pronaf, no estudo realizado por De Melo (2003) no município de Afogados da Ingazeira/PE, as mulheres acessaram o Pronaf, mas com um índice baixo e, na grande maioria, o de limite de crédito mais baixo, o "Pronaf B". Ela avalia que essa participação ocorre porque há um desinteresse dos maridos em acessarem uma linha de crédito com limite tão baixo, devido à burocracia e pouca rentabilidade.

Desta forma são elencadas as dificuldades do acesso ao Pronaf, que embora tenha contribuído substancialmente para o acesso ao crédito por parte dos assentados, precisa ser aprimorado para contemplar seus beneficiários de forma mais eficiente. São mencionados problemas que ocorrem também no âmbito institucional quando há desencontro de informações entre agentes bancários e técnicos de extensão rural (FERNANDES, 2008, p.19).

Diferentemente, no assentamento Monte Alegre, as mulheres não têm tido acesso ao Pronaf Mulher, embora já tenha havido um "mutirão de projetos" elaborados pelo ITESP nos anos entre 2004 a 2007, mas que resultou em um endividamento das famílias que obtiveram o crédito uma vez que os projetos foram realizados como resposta do órgão às pressões políticas da época e não foram elaborados de maneira conjunta. $\mathrm{O}$ funcionário do Itesp entrevistado nos descreveu este episódio e ficou nítido em suas falas o descontentamento nesta ocasião:

[...] houve uma pressão política aqui no município, reuniu-se um número grande de mulheres e foram até Brasília e aí eles achavam que o Pronaf Mulher era uma dívida que ia fazer para a mulher e isso não ia ter uma consequência, um pagamento, esse tipo de coisa. E aí houve uma pressão muito grande, houveram várias reuniões que foram feitas no assentamento, desse partido político com as mulheres do assentamento e por sua vez os maridos e mulheres vieram para cima de nós. A gente explicou, mas eles quiseram mesmo assim que fosse feito o projeto e então foi feito. O que resultou em uma inadimplência enorme depois, quando começou a vencer. Porque eles já tinham crédito, já tinham financiamento, então foi mais um. Só que aí quando começou a vencer, o partido político, as pessoas, aí some (Funcionário Itesp, 2016).

Esta pressão política ocorreu como forma de pressionar os agentes públicos para a realização do Pronaf Mulher. Embora tenham sido elaborados, o funcionário não pode afirmar que todos os projetos foram aprovados, já que segundo ele, o banco não transmite estas informações. Ocorre que neste episódio, conforme já foi mencionado, os projetos foram elaborados com o único propósito de atender à pressão política e, portanto, direcionavam a obtenção de crédito para a execução de atividades que geralmente são de maior responsabilidade masculina. A maior parte dos projetos, conforme descreveu o funcionário, foi destinado para obtenção de gado de corte, seguido de gado leiteiro e houve um projeto para perfuração de um poço artesiano. Este episódio reflete os entraves existentes em uma política pública que não leva em consideração as relações de gênero existentes.

O ACESSO CASSADO aOS DADOS: REFLEXOS DA DESVALORIZAÇÃo DA MUlher no Pronaf?

Conforme destacado no trabalho "Cirandas do Pronaf para Mulheres", publicado em 2005, o acesso a informações para elaborar, executar e avaliar políticas públicas é essencial. Contudo, embora já tenham se passado 11 anos da criação do Pronaf Mulher como uma linha específica de crédito, existem problemas relativos à divulgação e acesso aos dados que dificultam acompanhar a situação desta modalidade ao longo do tempo. Embora não seja o objetivo central deste estudo, é primordial que se destaque a dificuldade de obter dados que possibilitem a avaliação do acesso das mulheres a este crédito, principalmente em nível local. Houve, ao longo do desenvolvimento da pesquisa, tentativas frustradas de comunicação oficial com a agência do Banco do Brasil em Araraquara responsável por avaliar e aprovar o financiamento do Pronaf Mulher. Além disso, os sites institucionais vinculados ao Pronaf não fornecem dados detalhados relacionados à escala estadual, tampouco municipal. Existem indicações de locais online para obter essas informações, mas ao acessar os endereços nos deparamos com informações incompletas, confusas ou inexistentes.

É o caso, por exemplo, do Portal Brasileiro de Dados Abertos em que consta um link sobre indicadores do Pronaf, mas que, ao acessá-lo, direciona o usuário a uma página com informações desconfiguradas. Outro caso relevante é o da Matriz de Dados do Crédito Rural vinculada ao Banco Central do Brasil. Neste site é apresentada uma extensa variável de informações relacionadas ao crédito rural e apresenta como opção de consulta verificar alguns dados relacionados ao Pronaf a partir do ano de 2013, já 
que nos anos anteriores as informações estão sistematizadas no Anuário Estatístico de Crédito Rural. São sites com informações de difícil acesso e, às vezes, desconfiguradas. Ainda sobre os Anuários Estatísticos de Crédito Rural, salientamos que eles abrangem os anos de 1999 até 2013, todavia não fornecem a descrição das linhas do Pronaf nos dados apresentados. As estatísticas, neste caso, se convertem em barreiras que impedem o efetivo conhecimento da movimentação do Pronaf, especialmente para as mulheres.

Segundo dados do trabalho de Lourenço de Lima et al. (2013) existe uma concentração de acesso ao crédito nas regiões Nordeste e Sul, sendo que a região Nordeste concentra $61 \%$ das operações. A concentração do valor financeiro aplicado no Pronaf Mulher neste período também ocorre nestas duas regiões. Já o estado de São Paulo teve baixo acesso a esta modalidade de crédito, juntamente com a maior parte dos estados das regiões Norte e Sudeste.

No entanto, o aumento de contratos no ano de 2006 pode sugerir uma demanda política, já que foi o último ano do primeiro mandado do então presidente da república Luis Inácio Lula da Silva/PT. Podemos supor que este aumento se fez como estratégia política não só por parte do partido como dos próprios movimentos sociais, já que a continuidade do financiamento era incerta com a possibilidade de mudança de gestão. Esta suposição está embasada em uma das falas coletadas na entrevista do técnico do Itesp em Araraquara. Ainda sobre a fala do técnico é importante destacar que os projetos para as assentadas do Monte Alegre não foram aprovados pelo banco, já que, segundo o técnico, foram elaborados cerca de 300 projetos e o número de contratos firmados em 2006, em todo o estado de São Paulo se limitou a 224 (LOURENÇO DE LIMA et al., 2013). O dado referido pelo técnico provavelmente se refere ao total de contratos do Pronaf neste ano, pois ele não soube diferenciar o que seria Pronaf Mulher do montante total. Conforme a discussão que se segue, é bem provável que não havia nenhum Pronaf Mulher dentre esses contratos, haja visto o maior acesso ao financiamento de mulheres por meio do Pronaf B.

Nos anos seguintes, o cenário e a distribuição desigual de contratos do Pronaf Mulher permaneceram. Ainda persiste uma concentração de contratos na região Nordeste e um número ínfimo de contratos firmados no estado de São Paulo (Quadro 1).

De acordo com os dados disponíveis na Matriz de Dados do Crédito Rural, dos 947 contratos firmados na região sudeste entre 2013 e 2016, apenas 5 foram no estado de São Paulo. Destes cinco, três foram para projetos relacionados à atividade agrícola e dois para a pecuária. Todos os cinco contratos foram para o financiamento de atividades consideradas investimento.

O baixo acesso das mulheres no estado de São Paulo ao Pronaf Mulher não significa, entretanto, que estas estão excluídas do acesso ao crédito rural. Conforme a fala de um funcionário do Banco do Brasil entrevistado neste trabalho, as mulheres acessam mais expressivamente o Pronaf B. Esta modalidade de crédito é mais conhecida por ser mais antiga, e sua preferência ocorre principalmente por não exigir uma série de obrigações impostas em outras modalidades, sobretudo por ser um empréstimo de baixo valor. Este acesso ao Pronaf B se configura como mais uma estratégia das mulheres para se inserirem nas políticas públicas, quando estas não são devidamente formuladas para contemplar a complexidade da existência das mulheres no espaço rural. Conforme o Quadro 2 demonstra, diferentemente do baixo acesso ao Pronaf Mulher, no caso dos dados relativos ao Pronaf que contempla outras modalidades, a presença das mulheres é bem maior, embora seja bem menos expressiva que a dos homens.

No município de Araraquara, embora não tenha sido firmado nenhum contrato do Pronaf Mulher, no período entre 2013 a 2016 houve 7 contratos de Pronaf que totalizaram o valor de R\$1.952.200,73, segundo os dados da Matriz de Dados do Crédito Rural. Não foi possível verificar quanto destes contratos foram realizados por mulheres, já que esse tipo de discriminação não consta nas informações. Restrição reveladora de que o acesso ao crédito ainda é considerado prioridade masculina.

Quadro 1 - Quantidade de Contratos Pronaf Mulher por Regiões.

\begin{tabular}{|l|c|}
\hline \multicolumn{1}{|c|}{ Região } & $2013-2016$ \\
\hline SUDESTE & 947 \\
\hline NORDESTE & 3.248 \\
\hline SUL & 459 \\
\hline NORTE & 755 \\
\hline CENTRO-OESTE & 41 \\
\hline TOTAL & 5.450 \\
\hline
\end{tabular}

Fonte: Matriz de Dados do Crédito Rural, 2016. 
Quadro 2 - Quantidade e valor dos contratos de Pronaf por Região, Uf e

\begin{tabular}{|c|c|c|c|c|}
\hline \multicolumn{5}{|c|}{ Gênero* } \\
\hline REGIÃO & UF & GÊNERO & $\begin{array}{c}\text { TOTAL DE } \\
\text { CONTRATOS }\end{array}$ & \begin{tabular}{|c|} 
VALOR DOS \\
CONTRATOS (RS) \\
\end{tabular} \\
\hline SUDESTE & & & 1.036 .225 & $17.055 .749 .671,51$ \\
\hline & MG & & 871.421 & $12.488 .466 .542,36$ \\
\hline & & MASCULINO & 658.228 & $10.904 .018 .625,07$ \\
\hline & & FEMININO & 213.193 & $1.584 .447 .917,29$ \\
\hline & SP & & 123.734 & $3.509 .135 .769,50$ \\
\hline & & \begin{tabular}{|l} 
MASCULINO \\
\end{tabular} & 103.030 & $2.991 .769 .987,81$ \\
\hline & & FEMININO & 20.704 & 517.365.781,69 \\
\hline & ES & & 134.550 & 3.128.907.363,74 \\
\hline & & MASCULINO & 109.265 & 2.567.831.530,24 \\
\hline & & FEMININO & 19.052 & $446.029 .650,31$ \\
\hline & RJ & & 22.887 & $449.706 .596,48$ \\
\hline
\end{tabular}

(*) Refere-se ao sexo do emitente pessoa física da operação

Fonte: Matriz de Dados do Crédito Rural, 2016.

O Pronaf Mulher no assentamento Monte Alegre: a CONFIRMAÇÃO DA EXCLUSÃO

Diante de toda esta dificuldade em obter dados oficiais que pudessem revelar a situação das mulheres rurais em Araraquara diante do Pronaf Mulher, optou-se por realizar algumas entrevistas com algumas mulheres do assentamento Monte Alegre e com os agentes mediadores envolvidos. Neste caso, o objetivo não foi mensurar a participação das mulheres do Monte Alegre no Pronaf Mulher, mas sim caracterizar a participação destas nas políticas públicas, incluindo a de crédito, como estratégia para obterem renda. Confirmou-se a constatação de que muitas mulheres desconheciam o Pronaf Mulher, mas almejavam se inserir em algum grupo ou organização que visasse renda.

As entrevistas realizadas revelam aspectos em comum, que corroboram com as dificuldades de acesso ao Pronaf Mulher no Estado de São Paulo, elucidadas com os dados apresentados anteriormente. A invisibilidade do trabalho, a exclusão na participação da decisão da destinação da renda do lote e a falta de informação referente ao Pronaf Mulher permearam as falas das assentadas entrevistadas.

Por exemplo, quando questionado o acesso ao Pronaf para a assentada A, ela nos contou que a mãe acessa todo ano o crédito, mas que não se trata da linha Pronaf Mulher. Reside no núcleo IV do assentamento Monte Alegre e já participou da diretoria da cooperativa que tem sede neste núcleo. Ela nos informou que ficou sabendo da existência da linha direcionada às mulheres em uma visita que realizou em um escritório da Companhia Nacional de Abastecimento (Conab), em São Paulo, há três anos atrás. Afirmou que não conhece nenhuma mulher no assentamento que tenha acessado a linha Pronaf Mulher.

Tratando-se dos agentes de assistência técnica, reiterou que os técnicos do Itesp nunca dispuseram algum material informativo sobre a existência do Pronaf Mulher na sede da cooperativa. Ela apontou que os técnicos fazem reunião uma vez por ano e quem perde a reunião fica sem as informações.

Quando questionada se haveria um interesse de outras mulheres pelo acesso ao Pronaf Mulher, no sentido de contribuir com o desenvolvimento de alguma atividade específica, a assentada A comentou sobre a dificuldade de uma renda direcionada às mulheres:

[...] hoje eu vejo, no meu trabalho aqui dentro, que são poucas mulheres. Quando fazemos um trabalho aqui, é uma ou duas que vêm. Não tem trabalho para a mulher, não tem trabalho voltado para a mulher. [...] então eu penso dessa forma, os trabalhos feitos com mulheres tendem a dar mais certo e são mais organizados porque têm mais foco, as mulheres se dedicam mais no que estão fazendo. [...] As mulheres não têm a renda específica delas. A não ser quando elas se juntam, que são poucas, porque só têm a padaria. E tem quem trabalha para fora como doméstica. Olha o tanto de terra que tem, vai trabalhar de faxineira para os outros? (Assentada A do Monte Alegre, 2016, pôr data).

Esta fala da assentada A revela dimensões que se escondem sob o discurso do trabalho familiar homogêneo. Embora a mão de obra empregada na produção do lote seja familiar, a destinação da renda não fica sob responsabilidade conjunta. Os projetos não são elaborados sob a 
perspectiva de uma agricultura familiar, ao contrário do idealizado pelos órgãos institucionais.

Outra assentada entrevistada que reside no núcleo IV do assentamento Monte Alegre (Assentada B) também evidenciou em suas falas a falta de informação referente ao funcionamento do Pronaf Mulher. A assentada respondeu que já ouviu falar sobre isso nas reuniões de mulheres de que participou, mas que não conhece ninguém que o projeto tenha saído do papel.

É importante mencionar que outras mulheres têm dificuldade em relatar os nomes dos créditos que tiveram acesso. Talvez por fatores que estejam relacionados ao tempo e à memória, mas esta falta de informação pode sugerir uma falta de acompanhamento das atividades financeiras do assentamento, que ficam sob responsabilidade dos homens e/ou evidenciar a falta de participação na elaboração dos projetos produtivos, o que distancia a efetiva participação das mulheres na elaboração dos documentos e as torna passivas de um recurso que já vem estruturado. A assentada B descreveu que os primeiros Pronafs a que teve acesso conseguiu pagar em dia, mas no projeto que apontava para a compra de gado leiteiro acabou se endividando, pois teve despesas com o problema de saúde de sua mãe. Neste caso a falta de informação consistente evidencia uma pouca apropriação das atividades desenvolvidas pelo Itesp para o lote. A entrevistada tem conhecimento sobre a política pública do Pronaf, e apesar de ter pouco conhecimento sobre o Pronaf Mulher, o que fica evidente na fala é a fragilidade dessa política no sentido de propiciar o desenvolvimento/empreendimento da produção familiar em decorrência do endividamento.

Entre episódios de conflito que ocorrem no assentamento, relacionados com políticas de crédito, foi relatado por uma assentada que foi forçada a aceitar um financiamento que não almejava (Assentada $\mathrm{C}$ ). Este financiamento era no valor de $\mathrm{R} \$ 9.000,00$ que seria usado para a aquisição de gado. Não aceitando ser contrariado, o marido na época a forçou assinar:

Nós chegamos a discutir até na frente da pessoa que estava fazendo o papel. Porque eu não queria pegar esse dinheiro, para que fazer dívida? E eu ainda tive que assinar. No final da história: meu marido chegou a me ameaçar para eu assinar. Ele chegou a falar que se ele não pegasse esse dinheiro eu morreria. Sofri muito na mão dele, muito, muito (Assentada C do Monte Alegre DATA, 2016).
O financiamento acabou sendo feito diante das ameaças sofridas e por conta da seca que matou o gado, o casal acabou se endividando. Posteriormente, o marido ficou doente e faleceu, assim a dívida ficou sob responsabilidade da assentada. Ela ainda está em situação de inadimplência, mas já realizou a negociação com o banco para poder quitar a dívida. Este relato é muito ilustrativo como expressão dos gargalos existentes no Pronaf e no Pronaf Mulher. Ainda que a assinatura conjunta tenha, em sua essência, a intenção de fomentar a discussão dos projetos produtivos entre homens e mulheres, na prática ela não é suficiente para a superação dos conflitos gerados pelas relações de redes reafirmadas pelo patriarcalismo.

\section{CONSIDERAÇõES FINAIS}

Podemos apontar que embora seja específico para as mulheres, o Pronaf Mulher não está sendo acessado pelas trabalhadoras no assentamento pesquisado, o que pode gerar a conclusão que não consiste, verdadeiramente, em uma política pública que leva em consideração as relações de gênero. Isso porque não pressupõe as assimetrias de poder existentes dentro do núcleo familiar das assentadas, assimetrias essas inerentes à sociedade patriarcal e, portanto, também presentes nas relações com os mediadores externos.

Analisando as falas das assentadas percebemos um descompasso em relação às necessidades produtivas das mulheres. $\mathrm{Na}$ realidade, durante a pesquisa empírica e refletindo as falas coletadas, percebemos que as mulheres assentadas não almejam mais uma jornada de trabalho, mas uma autonomia financeira, o poder de decidir onde investir sua renda, já que mesmo com a DAP sendo elaborada no nome do casal, o cartão para acesso ao crédito fica na posse do marido. Neste sentido, a melhor saída que gestores têm encontrado, no caso analisado, é associar a execução do Pronaf B às atividades das mulheres, o que geralmente não tem efeito satisfatório no aumento do poder de decisão das mulheres sobre a aplicação do recurso. No entanto, constatou-se que a dominação masculina se dá justamente nos momentos de decisão e controle sobre os recursos econômicos. Acredita-se que dificilmente o Pronaf Mulher consegue subverter esta lógica.

Por outro lado, a burocracia e a falta, de informação têm sido apontadas como grandes entraves de acesso das mulheres às políticas públicas. Além disso, o Pronaf Mulher se constitui enquanto uma modalidade de crédito voltada para a mulher, mas que não direciona o tipo de projeto produtivo a ser elaborado. Desta forma, o acesso pode ocorrer, mas sem nenhuma 
eficiência no sentido de corrigir as desigualdades de renda existentes no lote. A dificuldade em acessar os dados do Pronaf Mulher corrobora com a pouca relevância dada a essa política por parte do Estado.

Sendo assim, o Pronaf Mulher promove avanços no sentido da cidadania feminina, uma vez que se faz como o reconhecimento governamental das assentadas como trabalhadoras rurais. Entretanto, ainda que as políticas públicas específicas para as mulheres não consigam transpor as barreiras do machismo na sua fase de implementação, as mulheres assentadas acabam construindo outras estratégias para se inserir no processo produtivo. Por meio do enfrentamento político, da auto-organização e da articulação política com o poder local elas não só se fazem ouvidas como conseguem captar suas demandas transformando-as em reivindicações políticas, como foi o caso das mulheres da padaria que conquistaram um espaço produtivo por meio do Orçamento Participativo e das relações com diversos outros agentes do território. A maneira de fazer política desconstrói a ideia de que a mobilização política só se faz em espaços formais e legitimados.

Sem o longo percurso para o acesso aos dados - muitas vezes frustrado -, e sem a constatação de sua invisibilidade, este estudo não teria podido contestar as armadilhas que transformam o Pronaf Mulher, na maioria das vezes, em uma idealização ou uma promessa típica das ações patrocinadas por uma cidadania tutelada. Constatou-se que as políticas públicas de microcrédito não têm clareza e aplicabilidade efetiva enquanto projeto de desenvolvimento, além de trazerem em seu bojo um conteúdo machista muito forte, que nos leva a associá-lo a uma mera mudança terminológica. No tocante aos créditos e, especialmente ao Pronaf Mulher, pode-se dizer que não foram rompidas as teias que transformam muitas vezes os benefícios concedidos às mulheres em expressões de uma ideologia machista camuflada.

\section{REFERÊNCIAS}

AZEVEDO, L. A. A Formação Social do Brasil e suas 'cegueiras' de gênero. In: VIII Jornada Internacional de Políticas Públicas, 2017, São Luís. Anais da VIII JOINPP, 2017.

ALVES, M. F. P. Dificuldades no acesso ao crédito pelas mulheres rurais. Discutindo a experiência do Pronaf Mulher no Oeste Potiguar. In: VII Congresso Latino Americano de Sociologia Rural. 2012. p. 20-24.
BANCO DO BRASIL. Disponível em: https://www.bb.com.br/docs/pub/ siteEsp/agro/dwn/TabelaAF.pdf. Acesso em: set. 2018.

BARONE, L. A. et al. Considerações acerca da produção nos assentamentos do Pontal do Paranapanema. Retratos de Assentamentos, v. 15, p. 135156,2012

BARONE, L. A. Conflito e Cooperação: o jogo das racionalidades sociais e o campo político num assentamento de reforma agrária. (Tese de Doutorado). Programa de Pós-Graduação em Sociologia, FCL/Unesp, Araraquara - SP, 2002.

BELLACOSA, J. M.; HOFFMANN, M. O cerco dos canaviais: contradições e conflitos nos assentamentos rurais. Agrária (São Paulo. Online), [S.1.], n. 13, p. 111-136, dec. 2010. ISSN 1808-1150. Disponível em: $<\mathrm{http}$ //revistas.usp.br/agraria/article/view/45572/49598>. Acesso em: 03 nov. 2016. doi:http://dx.doi.org/10.11606/issn.1808-1150.v0i13p111-136.

BRASIL. Ministério do Desenvolvimento Agrário. Secretaria Especial de Agricultura Familiar e do Desenvolvimento Agrário. Acesso em: set. 2018.

BRUMER, A.; SPANAVELLO, R. M. O papel dos mediadores no acesso das mulheres ao Pronaf mulher. Revista Anthropológicas, v. 23 p. 93-117, 2012.

CAMPOI, A. M. Sistemas de produção e estratégias de vida para a permanência na terra: umestudonoprojetodeassentamento MonteAlegreAraraquara-SP. (Dissertação de mestrado). Araraquara: UNIARA, 2005.183p.

DE MELO, L. Relações de Gênero na Agricultura Familiar: o caso do Pronaf em Afogados da Ingazeira - PE. Tese (Doutorado em Sociologia). Universidade Federal de Pernambuco. Programa de Pós-Graduação em Sociologia, Recife, 2003.

ESMERALDO, G. G. S. L. Ruídos com marcas de transgressões ancoradas em Mulheres Assentadas. In: Adriana L. Lopes; Andrea Butto. (Org.). 
Mulheres na Reforma Agrária. A experiência recente no Brasil. 1ed. Brasília: MDA, 2008, v. 14, p. 185-216.

FERRANTE, V. L. S. B. A chama verde dos canaviais: uma história das lutas dos boias-frias. Araraquara. Tese (Livre-Docência) - Faculdade de Ciências e Letras, Universidade Estadual Paulista, 1992. 589p.

FERRANTE, V.L.S.B., DUVAL, H.C. Vozes e Ações das mulheres na trajetória dos assentamentos rurais. In: FERRANTE, V.L.S.B.; WHITAKER, D.C.A. (Orgs). Retratos de Assentamentos. Araraquara, v.12, n. 1, p. 391 $-418,2009$.

FERRANTE, V.L.S.B. et al. Assentamento e Desenvolvimento: Diagnósticos Rurais. Realização de pesquisa de campo junto aos assentados da Reforma Agrária na região Central, para análise de sua inserção na economia local e da recepção, implementação e execução das políticas públicas realizadas pelo Incra - SP. Araraquara. 2012. 211p. (Série texto técnico CRT/SP/N $100000 / 2010$ ).

FERNANDES, S. A. Gênero e Políticas de Crédito: o Pronaf-Mulher em Santa Catarina. Dissertação. UFSC, Florianópolis, 2008.

Galgani Hernandez, C. O. Política de Crédito Rural com perspectiva de gênero: um meio de "empoderamento" para as mulheres rurais? 2009. Tese. (Doutorado) - Faculdade de Ciências Econômicas. Universidade Federal do Rio Grande do Sul. Porto Alegre.

BUTTO, A.; HORA, K. E. R. Mulheres e Reforma Agrária no Brasil. In: BUTTO, A; LOPES, A. (Org.). Mulheres na Reforma Agrária. 1ed .Brasília: NEAD/MDA, 2008, v. 1, p. 19-38.

LOURENÇO DE LIMA et al. Crédito Rural: uma análise da atuação e características do Pronaf Mulher. Econômico, v.16, n.32, p.22, 2013.

MATTEI, L. et al. Pronaf 10 anos: mapa da produção acadêmica. IICA, 2006.
MIGUEL, L. F; BIROLI, F. Feminismo e política: uma introdução. São Paulo: Boitempo, 2014

MOLYNEUX, M. D. 'The "Neoliberal Turn" and the New Social Policy in Latin America: How Neoliberal, How New?' Development and Change, 39(5), pp.775-797, 2008.

NADER, M. B. A presença feminina no mercado de trabalho no Brasil e no Espírito Santo: dos tempos coloniais aos dias atuais. Dimensões - Revista de História da Ufes. Vitória: Ufes, n. 17, 2005.

SILIPRANDI, E. Mulheres agricultoras no Brasil: sujeitos políticos na luta por soberania e segurança alimentar. In:Lagarde, M.; Valcarcel, A. (Org.). Pensamiento Iberoamericano:feminismo, gênero e igualdade. Madrid: Egraf,2011. p. 169-183. Disponível em: $<$ https://dialnet.unirioja. es/servlet/articulo? codigo $=3710909>$.

SOUZA, C. Políticas públicas: uma revisão da literatura. Sociologias, Porto Alegre, v. 8, n. 16, p. 20-45, 2006.

ZORZI, $A$. Uma análise crítica da noção de empoderamento com base no acesso das agricultoras ao Pronaf-Mulher em Ijuí - RS. Dissertação (Mestrado em Sociologia), Instituto de Filosofia e Ciências Humanas. Universidade Federal do Rio Grande do Sul. Porto Alegre, 2008.

WEBER, M. Sociologia da dominação. In: WEBER, M. Economia e sociedade. Brasília: UnB, p. 187-223, 1991. 